\title{
Editorial
}

\section{Simply Online? Lessons from Virtual Scientific Conferences for the Post-COVID-19 Era}

\author{
Rüdiger E. Scharf ${ }^{1}$ \\ 1 Program in Cellular and Molecular Medicine, Boston Children's \\ Hospital, Harvard Medical School, Boston, Massachusetts, USA
}

Hämostaseologie 2021;41:97-98.

The 2021 Annual Meeting of the Society of Thrombosis and Hemostasis Research (GTH) is over, and we have witnessed the first GTH online congress. From a conference participant's view, what are the impressions of and experiences with the online-only format in comparison to traditional face-to-face conferences on-site? Which memories of the Lausanne event do we share and which are the perspectives for future GTH meetings?

The Congress President had designed an outstanding scientific program, in which this year's multifaceted congress motto "Across Borders" was elucidated and discussed from various perspectives. ${ }^{1}$ The plenary, state-of-the-art, and keynote lectures were presented by excellent invited speakers, each of whom an expert in his/her field. These sessions and the newly established category of master classes covered a broad spectrum of interdisciplinary or specific topics related to basic science, translational research, and clinical research. Oral and poster presentations, educational sessions and workshops, and satellite symposia sponsored by industrial partners completed the comprehensive congress program. In this respect, the Lausanne congress was, on a high scientific level "business as usual" but, by contrast to all other GTH meetings, simply online. ${ }^{2}$

\section{Simply Online}

In fact, I assume that this slogan was selected carefully by the Congress President to truly reflect an ambiguous meaning. Simply online can refer to the easy and convenient access of scientists and delegates to attend and participate in the congress activities. However, the slogan may also express a kind of Swiss understatement since it was anything but simple to organize, implement and operate the digital platforms prior to, during, and after the Lausanne meeting. Thus, the media center, otherwise an easy-to-run check-in basis for speakers, became the communication nerve center and heart chamber of the e-congress. This year's Congress President and his team together with the agency Meister ConCept did a marvelous job in the pioneering work for the GTH to run online platforms for the presentations by speakers, their interaction with the audience ( $\mathrm{Q}-\mathrm{A}$ sessions), the networking among congress attendees, and the interaction with industrial partners and sponsors. No apparent errors or technical slip-ups occurred and if so, the backstage troubleshooting was perfect.

\section{... Worth Experiencing}

This year, the often-quoted "take-home messages" to the audience were unnecessary not because of lack of important scientific information during the 2021 Congress but simply due to the fact that relevant messages, recommendations, and conclusions were delivered straight forward to the congress attendees' home. Importantly, the "24/7" access of research communications to the audience permitted a maximum of individual convenience and flexibility. This service also permitted to attend various sessions including the huge number of master classes and satellite symposia in a sequential manner instead of being in conflict to select topics of interest that had otherwise been presented in simultaneous sessions. Specifically, recordings of the presentations allowed talks to be paused or rewound in case that one missed some details or had a need to spend more time when pondering a crucial slide. This together with other aspects of the Lausanne online experience is also discussed in Professor Alberio's editorial to this issue of Hämostaseologie - Progress in Haemostasis. ${ }^{3}$

Overall, I am convinced that the online presentations of the 2021 Congress (and their post-conference accessibility) provided a higher density of scientific information and a higher sustainability than any traditional GTH on-site meeting before. Thus, communication of scientific information,
Address for correspondence Rüdiger E. Scharf, MD, PhD, FAHA, Emeritus Chair and Director of Hemostasis, Hemotherapy, and Transfusion Medicine, Heinrich Heine University Medical Center, Moorenstrasse 5, D-40225 Dusseldorf, Germany (e-mail: rscharf@uni-duesseldorf.de).
() 2021. Thieme. All rights reserved. Georg Thieme Verlag KG,

Rüdigerstraße 14,

70469 Stuttgart, Germany

received

March 16, 2021

accepted

March 16, 2021
DOI https://doi.org/ 10.1055/a-1411-9101. ISSN 0720-9355. 
the major conference objective of the Society has been accomplished - but at what price? No reunion with colleagues and friends, no scientific face-to-face discussions, no on-site exchange with industrial partners, no local social events, no opportunity to visit Lausanne and to enjoy the encharming environment of this part of Switzerland. We now recognize that the attendance of in-person scientific conferences has been a true professional privilege that we had easily become accustomed to and that we now regretfully miss in times of COVID-19.

\section{Lessons from the GTH Online Congress}

Trivial to say that life after the SARS-CoV-2 pandemic will be different from before. The experiences we are gaining now offer an opportunity for future endeavors. This will be also true for scientific societies.

My personal experience during the virtual 2021 Congress, focusing on scientific communication and sustained information is a small but important selection only. There are many other aspects that can be provided by digital platforms and online presentations to set new standards of communication and interaction. ${ }^{4}$ Some of these opportunities are summarized in Professor Alberio's editorial. ${ }^{3}$ Others are discussed elsewhere. ${ }^{5}$ For example, these possible innovations include increasing the participation of hitherto underrepresented scientists in conferences, acceleration of knowledge transfer, promotion and training opportunities of early-career scientists, and specifically targeted analysis of meeting statistics.
The need for organizing virtual meetings during the COVID-19 pandemic offers the opportunity to scrutinize in-person formats of conventional conferences, to review the input-output or cost-benefit relationship, and to reform the traditional methods of organizing and performing academic conferences. It remains to be seen what the long-term consequences of online instead of face-to-face communication will be. ${ }^{6}$ The requirement for personal and social interactions and conviviality among scientists and health care professionals will persist. Thus, hybrid conferences combining on-site and online presentations or real and digital interactions appear to be an appropriate solution in the future.

\section{Conflict of Interest}

The author declares that he has no conflict of interest.

\section{References}

1 Alberio L. GTH 2021: Across Borders. Hamostaseologie 2021;41 (01):5-8

2 Alberio L. GTH 2021: simply online ... worth experiencing. Hamostaseologie 2020;40(05):558-559

3 Alberio L. GTH 2021: The first online experience! useful for future meetings? Hamostaseologie 2021;41(02):100-102

4 Sarabipour S. Virtual conferences raise standards for accessibility and interactions. eLife 2020;9:e62668. Doi: 10.7554/eLife.62668

5 Scharf RE. Virtual scientific conferences: challenges and opprotunities (submitted). 2021

6 Scharf RE. How the COVID-19 pandemic impacts lives of life scientists. Hamostaseologie 2021;41(01):9-13 